\title{
Coupled fixed point theorems on partially ordered $G$-metric spaces
}

\author{
Erdal Karapınar ${ }^{1}$, Poom Kumam ${ }^{2,3}$ and Inci M Erhan ${ }^{1 *}$
}

"Correspondence: ierhan@atilim.edu.tr

'Department of Mathematics, Atilim University, Incek, Ankara 06836, Turkey

Full list of author information is available at the end of the article

\begin{abstract}
The purpose of this paper is to extend some recent coupled fixed point theorems in the context of partially ordered G-metric spaces in a virtually different and more natural way.

MSC: 46N40;47H10; 54H25; 46T99

Keywords: coupled fixed point; coupled coincidence point; mixed g-monotone property; ordered set; G-metric space
\end{abstract}

\section{Introduction and preliminaries}

The notion of metric space was introduced by Fréchet [1] in 1906. In almost all fields of quantitative sciences which require the use of analysis, metric spaces play a major role. Internet search engines, image classification, protein classification (see, e.g., [2]) can be listed as examples in which metric spaces have been extensively used to solve major problems. It is conceivable that metric spaces will be needed to explore new problems that will arise in quantitative sciences in the future. Therefore, it is necessary to consider various generalizations of metrics and metric spaces to broaden the scope of applied sciences. In this respect, cone metric spaces, fuzzy metric spaces, partial metric spaces, quasi-metric spaces and $b$-metric spaces can be given as the main examples. Applications of these different approaches to metrics and metric spaces make it evident that fixed point theorems are important not only for the branches of mainstream mathematics, but also for many divisions of applied sciences.

Inspired by this motivation Mustafa and Sims [3] introduced the notion of a G-metric space in 2004 (see also [4-7]). In their introductory paper, the authors investigated versions of the celebrated theorems of the fixed point theory such as the Banach contraction mapping principle [8] from the point of view of G-metrics. Another fundamental aspect in the theory of existence and uniqueness of fixed points was considered by Ran and Reurings [9] in partially ordered metric spaces. After Ran and Reurings' pioneering work, several authors have focused on the fixed points in ordered metric spaces and have used the obtained results to discuss the existence and uniqueness of solutions of differential equations, more precisely, of boundary value problems (see, e.g., [10-20]). Upon the introduction of the notion of coupled fixed points by Guo and Laksmikantham [14], Gnana-Bhaskar and Lakshmikantham [15] obtained interesting results related to differential equations with periodic boundary conditions by developing the mixed monotone property in the context of partially ordered metric spaces. As a continuation of this trend, 
many authors conducted research on the coupled fixed point theory and many results in this direction were published (see, for example, [21-35]).

In this paper, we prove the theorem that amalgamates these three seminal approaches in the study of fixed point theory, the so called G-metrics, coupled fixed points and partially ordered spaces.

We shall start with some necessary definitions and a detailed overview of the fundamental results developed in the remarkable works mentioned above. Throughout this paper, $\mathbb{N}$ and $\mathbb{N}^{*}$ denote the set of non-negative integers and the set of positive integers respectively.

Definition 1 (See [3]) Let $X$ be a non-empty set, $G: X \times X \times X \rightarrow \mathbb{R}^{+}$be a function satisfying the following properties:

(G1) $G(x, y, z)=0$ if $x=y=z$,

(G2) $G(x, x, y)>0$ for all $x, y \in X$ with $x \neq y$,

(G3) $G(x, x, y) \leq G(x, y, z)$ for all $x, y, z \in X$ with $y \neq z$,

(G4) $G(x, y, z)=G(x, z, y)=G(y, z, x)=\cdots$ (symmetry in all three variables),

(G5) $G(x, y, z) \leq G(x, a, a)+G(a, y, z)$ for all $x, y, z, a \in X$ (rectangle inequality).

Then the function $G$ is called a generalized metric or, more specially, a $G$-metric on $X$, and the pair $(X, G)$ is called a $G$-metric space.

It can be easily verified that every $G$-metric on $X$ induces a metric $d_{G}$ on $X$ given by

$$
d_{G}(x, y)=G(x, y, y)+G(y, x, x), \quad \text { for all } x, y \in X .
$$

Trivial examples of G-metric are as follows.

Example 2 Let $(X, d)$ be a metric space. The function $G: X \times X \times X \rightarrow[0,+\infty)$, defined by

$$
G(x, y, z)=\max \{d(x, y), d(y, z), d(z, x)\}
$$

or

$$
G(x, y, z)=d(x, y)+d(y, z)+d(z, x)
$$

for all $x, y, z \in X$, is a $G$-metric on $X$.

The concepts of convergence, continuity, completeness and Cauchy sequence have also been defined in [3].

Definition 3 (See [3]) Let $(X, G)$ be a $G$-metric space, and let $\left\{x_{n}\right\}$ be a sequence of points of $X$. We say that $\left\{x_{n}\right\}$ is $G$-convergent to $x \in X$ if $\lim _{n, m \rightarrow+\infty} G\left(x, x_{n}, x_{m}\right)=0$, that is, if for any $\varepsilon>0$, there exists $N \in \mathbb{N}$ such that $G\left(x, x_{n}, x_{m}\right)<\varepsilon$ for all $n, m \geq N$. We call $x$ the limit of the sequence and write $x_{n} \rightarrow x$ or $\lim _{n \rightarrow+\infty} x_{n}=x$.

Proposition 4 (See [3]) Let $(X, G)$ be a G-metric space. The following statements are equivalent:

(1) $\left\{x_{n}\right\}$ is G-convergent to $x$,

(2) $G\left(x_{n}, x_{n}, x\right) \rightarrow 0$ as $n \rightarrow+\infty$, 
(3) $G\left(x_{n}, x, x\right) \rightarrow 0$ as $n \rightarrow+\infty$,

(4) $G\left(x_{n}, x_{m}, x\right) \rightarrow 0$ as $n, m \rightarrow+\infty$.

Definition 5 (See [3]) Let $(X, G)$ be a $G$-metric space. A sequence $\left\{x_{n}\right\}$ is called G-Cauchy sequence if for any $\varepsilon>0$, there is $N \in \mathbb{N}$ such that $G\left(x_{n}, x_{m}, x_{l}\right)<\varepsilon$ for all $m, n, l \geq N$, that is, $G\left(x_{n}, x_{m}, x_{l}\right) \rightarrow 0$ as $n, m, l \rightarrow+\infty$.

Proposition 6 (See [3]) Let $(X, G)$ be a G-metric space. The following statements are equivalent:

(1) The sequence $\left\{x_{n}\right\}$ is G-Cauchy.

(2) For any $\varepsilon>0$, there exists $N \in \mathbb{N}$ such that $G\left(x_{n}, x_{m}, x_{m}\right)<\varepsilon$, for all $m, n \geq N$.

Definition 7 (See [3]) A G-metric space $(X, G)$ is called $G$-complete if every G-Cauchy sequence is $G$-convergent in $(X, G)$.

Definition 8 Let $(X, G)$ be a $G$-metric space. A mapping $F: X \times X \times X \rightarrow X$ is said to be continuous if for any three $G$-convergent sequences $\left\{x_{n}\right\},\left\{y_{n}\right\}$ and $\left\{z_{n}\right\}$ converging to $x, y$ and $z$ respectively, $\left\{F\left(x_{n}, y_{n}, z_{n}\right)\right\}$ is $G$-convergent to $F(x, y, z)$.

We define below $g$-ordered complete $G$-metric spaces.

Definition 9 Let $(X, \preceq)$ be a partially ordered set, $(X, G)$ be a $G$-metric space and $g: X \rightarrow$ $X$ be a mapping. A partially ordered $G$-metric space, $(X, G, \preceq)$, is called $g$-ordered complete if for each $G$-convergent sequence $\left\{x_{n}\right\}_{n=0}^{\infty} \subset X$, the following conditions hold:

$\left(O C_{1}\right)$ If $\left\{x_{n}\right\}$ is a non-increasing sequence in $X$ such that $x_{n} \rightarrow x^{*}$, then $g x^{*} \preceq g x_{n} \forall n \in \mathbb{N}$. $\left(O C_{2}\right)$ If $\left\{x_{n}\right\}$ is a non-decreasing sequence in $X$ such that $x_{n} \rightarrow x^{*}$, then $g x^{*} \succeq g x_{n} \forall n \in \mathbb{N}$.

In particular, if $g$ is the identity mapping in $\left(O C_{1}\right)$ and $\left(O C_{2}\right)$, the partially ordered $G$-metric space, $(X, G, \preceq)$, is called ordered complete.

We next recall some basic notions from the coupled fixed point theory. In 1987 Guo and Lakshmikantham [14] defined the concept of a coupled fixed point. In 2006, in order to prove the existence and uniqueness of the coupled fixed point of an operator $F: X \times$ $X \rightarrow X$ on a partially ordered metric space, Gnana-Bhaskar and Lakshmikantham [15] reconsidered the notion of a coupled fixed point via the mixed monotone property.

Definition 10 ([15]) Let $(X, \preceq)$ be a partially ordered set and $F: X \times X \rightarrow X$. The mapping $F$ is said to have the mixed monotone property if $F(x, y)$ is monotone non-decreasing in $x$ and is monotone non-increasing in $y$, that is, for any $x, y \in X$,

$$
x_{1} \preceq x_{2} \quad \Rightarrow \quad F\left(x_{1}, y\right) \preceq F\left(x_{2}, y\right), \quad \text { for } x_{1}, x_{2} \in X,
$$

and

$$
y_{1} \preceq y_{2} \quad \Rightarrow \quad F\left(x, y_{2}\right) \preceq F\left(x, y_{1}\right), \quad \text { for } y_{1}, y_{2} \in X .
$$

Definition 11 ([15]) An element $(x, y) \in X \times X$ is called a coupled fixed point of the mapping $F: X \times X \rightarrow X$ if

$$
x=F(x, y) \text { and } y=F(y, x) .
$$


The results in [15] were extended by Lakshmikantham and Ćirić in [16] by defining the mixed $g$-monotone property.

Definition 12 Let $(X, \preceq)$ be a partially ordered set, $F: X \times X \rightarrow X$ and $g: X \rightarrow X$. The function $F$ is said to have mixed $g$-monotone property if $F(x, y)$ is monotone $g$-nondecreasing in $x$ and is monotone $g$-non-increasing in $y$, that is, for any $x, y \in X$,

$$
g\left(x_{1}\right) \preceq g\left(x_{2}\right) \quad \Rightarrow \quad F\left(x_{1}, y\right) \preceq F\left(x_{2}, y\right), \quad \text { for } x_{1}, x_{2} \in X,
$$

and

$$
g\left(y_{1}\right) \preceq g\left(y_{2}\right) \quad \Rightarrow \quad F\left(x, y_{2}\right) \preceq F\left(x, y_{1}\right), \quad \text { for } y_{1}, y_{2} \in X \text {. }
$$

It is clear that Definition 12 reduces to Definition 10 when $g$ is the identity mapping.

Definition 13 An element $(x, y) \in X \times X$ is called a coupled coincidence point of the mappings $F: X \times X \rightarrow X$ and $g: X \rightarrow X$ if

$$
F(x, y)=g(x), \quad F(y, x)=g(y)
$$

and a common coupled fixed point of $F$ and $g$ if

$$
F(x, y)=g(x)=x, \quad F(y, x)=g(y)=y .
$$

Definition 14 The mappings $F: X \times X \rightarrow X$ and $g: X \rightarrow X$ are said to commute if

$$
g(F(x, y))=F(g(x), g(y)), \quad \text { for all } x, y \in X .
$$

Throughout the rest of the paper, we shall use the notation $g x$ instead of $g(x)$, where $g: X \rightarrow X$ and $x \in X$, for brevity. In [35], Nashine proved the following theorems.

Theorem 15 Let $(X, G, \preceq)$ be a partially ordered G-metric space. Let $F: X \times X \rightarrow X$ and $g: X \rightarrow X$ be mappings such that $F$ has the mixed $g$-monotone property, and let there exist $x_{0}, y_{0} \in X$ such that $g x_{0} \preceq F\left(x_{0}, y_{0}\right)$ and $F\left(y_{0}, x_{0}\right) \preceq g y_{0}$. Suppose that there exists $k \in\left[0, \frac{1}{2}\right)$ such that for all $x, y, u, v, w, z \in X$ the following holds:

$$
G(F(x, y), F(u, v), F(w, z)) \leq k[G(g x, g u, g w)+G(g y, g v, g z)],
$$

for all $g w \preceq g u \preceq g x$ and $g y \preceq g v \preceq g z$, where either $g u \neq g z$ or $g v \neq g w$. Assume the following hypotheses:

(i) $F(X \times X) \subseteq g(X)$,

(ii) $g(X)$ is G-complete,

(iii) $g$ is G-continuous and commutes with $F$.

Then $F$ and $g$ have a coupled coincidence point, that is, there exists $(x, y) \in X \times X$ such that $g x=F(x, y)$ and $g y=F(y, x)$. If $g u=g z$ and $g v=g w$, then $F$ and $g$ have a common fixed point, that is, there exists $x \in X$ such that $g x=F(x, x)=x$. 
Theorem 16 If in the above theorem, we replace the condition (ii) by the assumption that $X$ is g-ordered complete, then we have the conclusions of Theorem 15.

We next give the definition of G-compatible mappings inspired by the definition of compatible mappings in [13].

Definition 17 Let $(X, G)$ be a $G$-metric space. The mappings $F: X \times X \rightarrow X, g: X \rightarrow X$ are said to be $G$-compatible if

$$
\begin{aligned}
& \lim _{n \rightarrow \infty} G\left(g F\left(x_{n}, y_{n}\right), g F\left(x_{n}, y_{n}\right), F\left(g x_{n}, g y_{n}\right)\right) \\
& \quad=0=\lim _{n \rightarrow \infty} G\left(g F\left(x_{n}, y_{n}\right), F\left(g x_{n}, g y_{n}\right), F\left(g x_{n}, g y_{n}\right)\right)
\end{aligned}
$$

and

$$
\begin{aligned}
& \lim _{n \rightarrow \infty} G\left(g F\left(y_{n}, x_{n}\right), g F\left(y_{n}, x_{n}\right), F\left(g y_{n}, g x_{n}\right)\right) \\
& \quad=0=\lim _{n \rightarrow \infty} G\left(g F\left(y_{n}, x_{n}\right), F\left(g y_{n}, g x_{n}\right), F\left(g y_{n}, g x_{n}\right)\right),
\end{aligned}
$$

where $\left\{x_{n}\right\}$ and $\left\{y_{n}\right\}$ are sequences in $X$ such that $\lim _{n \rightarrow \infty} F\left(x_{n}, y_{n}\right)=\lim _{n \rightarrow \infty} g x_{n}=x$ and $\lim _{n \rightarrow \infty} F\left(y_{n}, x_{n}\right)=\lim _{n \rightarrow \infty} g y_{n}=y$ for all $x, y \in X$ are satisfied.

In this paper, we aim to extend the results on coupled fixed points mentioned above. Our results improve, enrich and extend some existing theorems in the literature. We also give examples to illustrate our results. This paper can also be considered as a continuation of the works of Berinde $[11,12]$.

\section{Main results}

We start with an example which shows the weakness of Theorem 15.

Example 18 Let $X=\mathbb{R}$. Define $G: X \times X \times X \rightarrow[0, \infty)$ by

$$
G(x, y, z)=|x-y|+|x-z|+|y-z|
$$

for all $x, y, z \in X$. Let $\preceq$ be usual order. Then $(X, G)$ is a $G$-metric space. Define a map $F: X \times X \rightarrow X$ by $F(x, y)=\frac{1}{8} x+\frac{5}{8} y$ and $g: X \rightarrow X$ by $g(x)=\frac{7 x}{8}$ for all $x, y \in X$. Let $x=u=z$. Then we have

$$
\begin{aligned}
G(F(x, y), F(u, v), F(z, w)) & =G\left(\frac{1}{8} x+\frac{5}{8} y, \frac{1}{8} u+\frac{5}{8} v, \frac{1}{8} z+\frac{5}{8} w\right) \\
& =\frac{5}{8}|v-y|+\frac{5}{8}|w-y|+\frac{5}{8}|w-v|,
\end{aligned}
$$

and

$$
\begin{aligned}
G(g x, g u, g z)+G(g y, g v, g w) & =G\left(\frac{x}{2}, \frac{u}{2}, \frac{z}{2}\right)+G\left(\frac{y}{2}, \frac{v}{2}, \frac{w}{2}\right) \\
& =\frac{7}{8}[|y-v|+|y-w|+|v-w|] .
\end{aligned}
$$


It is clear that there is no $k \in\left[0, \frac{1}{2}\right)$ for which the statement (1.4) of Theorem 15 holds. Notice, however, that $(0,0)$ is the unique coupled coincidence point of $F$ and $g$. In fact, it is a common fixed point of $F$ and $g$, that is, $F(0,0)=g 0=0$.

We now state our first result which successively guarantees the existence of a coupled coincidence point.

Theorem 19 Let $(X, \preceq)$ be a partially ordered set and $(X, G)$ be a $G$-complete $G$-metric space. Let $F: X \times X \rightarrow X$ and $g: X \rightarrow X$ be two mappings such that $F$ has the mixed $g$-monotone property on $X$ and

$$
\begin{aligned}
& G(F(x, y), F(u, v), F(w, z))+G(F(y, x), F(v, u), F(z, w)) \\
& \quad \leq k[G(g x, g u, g w)+G(g y, g v, g z)]
\end{aligned}
$$

for all $x, y, u, v, z, w \in X$ with $g x \succeq g u \succeq g w, g y \preceq g v \preceq g z$. Assume that $F(X \times X) \subset g(X), g$ is $G$-continuous and that $F$ and $g$ are G-compatible mappings. Suppose further that either

(a) $F$ is continuous or

(b) $(X, G, \preceq)$ is g-ordered complete.

Suppose also that there exist $x_{0}, y_{0} \in X$ such that $g x_{0} \preceq F\left(x_{0}, y_{0}\right)$ and $F\left(y_{0}, x_{0}\right) \preceq g y_{0}$. If $k \in[0,1)$, then $F$ and $g$ have a coupled coincidence point, that is, there exists $(x, y) \in(X \times X)$ such that $g(x)=F(x, y)$ and $g(y)=F(y, x)$.

Proof Let $x_{0}, y_{0} \in X$ be such that $g x_{0} \preceq F\left(x_{0}, y_{0}\right)$ and $F\left(y_{0}, x_{0}\right) \preceq g y_{0}$. Using the fact that $F(X \times X) \subset g(X)$, we can construct two sequences $\left\{x_{n}\right\}$ and $\left\{y_{n}\right\}$ in $X$ in the following way:

$$
g x_{n+1}=F\left(x_{n}, y_{n}\right), \quad g y_{n+1}=F\left(y_{n}, x_{n}\right), \quad n \in \mathbb{N}
$$

We shall prove that for all $n \geq 0$,

$$
g x_{n} \preceq g x_{n+1} \text { and } g y_{n} \succeq g y_{n+1} .
$$

Since $g x_{0} \preceq F\left(x_{0}, y_{0}\right)$ and $F\left(y_{0}, x_{0}\right) \preceq g y_{0}$ and $g x_{1}=F\left(x_{0}, y_{0}\right)$ and $F\left(y_{0}, x_{0}\right)=g y_{0}$, we have $g x_{0} \preceq g x_{1}$ and $g y_{1} \preceq g y_{0}$, that is, (2.5) holds for $n=0$. Assume that (2.5) holds for some $n>0$. Since $F$ has the mixed $g$-monotone property, from (2.4), we have

$$
g x_{n+1}=F\left(x_{n}, y_{n}\right) \preceq F\left(x_{n+1}, y_{n}\right) \preceq F\left(x_{n+1}, y_{n+1}\right)=g x_{n+2},
$$

and

$$
g y_{n+1}=F\left(y_{n}, x_{n}\right) \succeq F\left(y_{n+1}, x_{n}\right) \succeq F\left(y_{n+1}, x_{n+1}\right)=g y_{n+2}
$$

By mathematical induction, it follows that (2.5) holds for all $n \geq 0$, that is,

$$
g x_{0} \preceq g x_{1} \preceq g x_{2} \preceq \cdots \preceq g x_{n} \preceq g x_{n+1} \preceq g x_{n+2} \cdots,
$$

and

$$
g y_{0} \succeq g y_{1} \succeq g y_{2} \succeq \cdots \succeq g y_{n} \succeq g y_{n+1} \succeq g y_{n+2} \cdots
$$


If there exists $n_{0} \in \mathbb{N}$ such that $\left(g x_{n_{0}+1}, g y_{n_{0}+1}\right)=\left(g x_{n_{0}}, g y_{n_{0}}\right)$, then $F$ and $g$ have a coupled coincidence point. Indeed, in that case we would have

$$
\begin{gathered}
\left(g x_{n_{0}+1}, g y_{n_{0}+1}\right)=\left(F\left(x_{n_{0}}, y_{n_{0}}\right), F\left(y_{n_{0}}, x_{n_{0}}\right)\right)=\left(g x_{n_{0}}, g y_{n_{0}}\right) \\
\Longleftrightarrow \quad F\left(x_{n_{0}}, y_{n_{0}}\right)=g x_{n_{0}} \quad \text { and } \quad F\left(y_{n_{0}}, x_{n_{0}}\right)=g y_{n_{0}} .
\end{gathered}
$$

We suppose that $\left(g x_{n+1}, g y_{n+1}\right) \neq\left(g x_{n}, g y_{n}\right)$ for all $n \in \mathbb{N}$. More precisely, we assume that either $g x_{n+1}=F\left(x_{n}, y_{n}\right) \neq g x_{n}$ or $g y_{n+1}=F\left(y_{n}, x_{n}\right) \neq g y_{n}$.

For $n \in \mathbb{N}$, we set

$$
t_{n}=G\left(g x_{n+1}, g x_{n+1}, g x_{n}\right)+G\left(g y_{n+1}, g y_{n+1}, g y_{n}\right) .
$$

Then by using (2.3) and (2.6), for each $n \in \mathbb{N}$, we have

$$
\begin{aligned}
t_{n} & =G\left(g x_{n+1}, g x_{n+1}, g x_{n}\right)+G\left(g y_{n+1}, g y_{n+1}, g y_{n}\right) \\
& =G\left(F\left(x_{n}, y_{n}\right), F\left(x_{n}, y_{n}\right), F\left(x_{n-1}, y_{n-1}\right)\right)+G\left(F\left(y_{n}, x_{n}\right), F\left(y_{n}, x_{n}\right), F\left(y_{n-1}, x_{n-1}\right)\right) \\
& \leq k\left[G\left(g x_{n}, g x_{n}, g x_{n-1}\right)+G\left(g y_{n}, g y_{n}, g y_{n-1}\right)\right] \\
& =k t_{n-1},
\end{aligned}
$$

which yields that

$$
t_{n} \leq k^{n} t_{0}, \quad n \in \mathbb{N}
$$

Now, for all $m, n \in \mathbb{N}$ with $m>n$, by using rectangle inequality (G5) of G-metric and (2.10), we get

$$
\begin{aligned}
G( & \left(g x_{m}, g x_{m}, g x_{n}\right)+G\left(g y_{m}, g y_{m}, g y_{n}\right) \\
= & G\left(g x_{n}, g x_{m}, g x_{m}\right)+G\left(g y_{n}, g y_{m}, g y_{m}\right) \\
\leq & G\left(g x_{n}, g x_{n+1}, g x_{n+1}\right)+G\left(g x_{n+1}, g x_{m}, g x_{m}\right) \\
& +G\left(g y_{n}, g y_{n+1}, g y_{n+1}\right)+G\left(g y_{n+1}, g y_{m}, g y_{m}\right) \\
\leq & G\left(g x_{n}, g x_{n+1}, g x_{n+1}\right)+G\left(g x_{n+1}, g x_{n+2}, g x_{n+2}\right)+G\left(g x_{n+2}, g x_{m}, g x_{m}\right) \\
& +G\left(g y_{n}, g x_{n+1}, g y_{n+1}\right)+G\left(g y_{n+1}, g y_{n+2}, g y_{n+2}\right)+G\left(g y_{n+2}, g y_{m}, g y_{m}\right) \\
& \vdots \\
\leq & G\left(g x_{n}, g x_{n+1}, g x_{n+1}\right)+G\left(g x_{n+1}, g x_{n+2}, g x_{n+2}\right)+\cdots+G\left(g x_{m-1}, g x_{m}, g x_{m}\right) \\
& +G\left(g y_{n}, g y_{n+1}, g y_{n+1}\right)+G\left(g y_{n+1}, g y_{n+2}, g y_{n+2}\right)+\cdots+G\left(g y_{m-1}, g y_{m}, g y_{m}\right) \\
= & t_{n}+t_{n+1}+\cdots+t_{m-1} \\
\leq & \left(k^{n}+k^{n+1}+\cdots+k^{m-1}\right) t_{0} \\
\leq & \frac{k^{n}}{1-k} t_{0},
\end{aligned}
$$


which yields that

$$
\lim _{n, m \rightarrow+\infty} G\left(g x_{n}, g x_{m}, g x_{m}\right)+G\left(g y_{n}, g y_{m}, g y_{m}\right)=0 .
$$

Then by Proposition 6, we conclude that the sequences $\left\{g x_{n}\right\}$ and $\left\{g y_{n}\right\}$ are G-Cauchy.

Noting that $g(X)$ is $G$-complete, there exist $x, y \in g(X)$ such that $\left\{g x_{n}\right\}$ and $\left\{g y_{n}\right\}$ are $G$-convergent to $x$ and $y$ respectively, i.e.,

$$
\begin{aligned}
& \lim _{n \rightarrow+\infty} F\left(x_{n}, y_{n}\right)=\lim _{n \rightarrow+\infty} g x_{n+1}=x, \\
& \lim _{n \rightarrow+\infty} F\left(y_{n}, x_{n}\right)=\lim _{n \rightarrow+\infty} g y_{n+1}=y .
\end{aligned}
$$

Since $F$ and $g$ are $G$-compatible mappings, by (2.11), we have

$$
\begin{aligned}
& \lim _{n \rightarrow \infty} G\left(g F\left(x_{n}, y_{n}\right), F\left(g x_{n}, g y_{n}\right), F\left(g x_{n}, g y_{n}\right)\right)=0, \\
& \lim _{n \rightarrow \infty} G\left(g F\left(y_{n}, x_{n}\right), F\left(g y_{n}, g x_{n}\right), F\left(g y_{n}, g x_{n}\right)\right)=0 .
\end{aligned}
$$

Suppose that the condition (a) holds. For all $n>0$, we have

$$
\begin{aligned}
& G\left(g x, F\left(g x_{n}, g y_{n}\right), F\left(g x_{n}, g y_{n}\right)\right)+G\left(g y, F\left(g y_{n}, g x_{n}\right), F\left(g y_{n}, g x_{n}\right)\right) \\
& \quad \leq G\left(g x, g F\left(x_{n}, y_{n}\right), g F\left(x_{n}, y_{n}\right)\right)+G\left(g F\left(x_{n}, y_{n}\right), F\left(g x_{n}, g y_{n}\right), F\left(g x_{n}, g y_{n}\right)\right) \\
& \quad+G\left(g y, g F\left(y_{n}, x_{n}\right), g F\left(y_{n}, x_{n}\right)\right)+G\left(g F\left(y_{n}, x_{n}\right), F\left(g y_{n}, g x_{n}\right), F\left(g y_{n}, g x_{n}\right)\right) .
\end{aligned}
$$

Letting $n \rightarrow \infty$ in the above inequality, using (2.11), (2.12) and the continuities of $F$ and $g$, we have

$$
\lim _{n \rightarrow \infty} G(g x, F(x, y), F(x, y))+G(g y, F(y, x), F(y, x))=0 .
$$

Hence, we derive that $g x=F(x, y)$ and $g y=F(y, x)$, that is, $(x, y) \in X^{2}$ is a coupled coincidence point of $F$ and $g$. Suppose that the condition (b) holds. By (2.8), (2.9) and (2.11), we have

$$
g g x \preceq g x \text { and } \quad g g y \succeq g y .
$$

Due to the fact that $F$ and $g$ are $G$-compatible mappings and $g$ is continuous, by (2.11) and (2.12), we have

$$
\begin{aligned}
& \lim _{n \rightarrow \infty} g g x_{n}=g x=\lim _{n \rightarrow \infty} g F\left(x_{n}, y_{n}\right)=\lim _{n \rightarrow \infty} F\left(g x_{n}, g y_{n}\right), \\
& \lim _{n \rightarrow \infty} g g y_{n}=g y=\lim _{n \rightarrow \infty} g F\left(y_{n}, x_{n}\right)=\lim _{n \rightarrow \infty} F\left(g y_{n}, g x_{n}\right) .
\end{aligned}
$$

Keeping (2.15) and (2.16) in mind, we consider now

$$
\begin{aligned}
& G(g x, F(x, y), F(x, y))+G(g y, F(y, x), F(y, x)) \\
& \quad \leq G\left(g x, g g x_{n+1}, g g x_{n+1}\right)+G\left(g g x_{n+1}, F(x, y), F(x, y)\right)
\end{aligned}
$$




$$
\begin{aligned}
& +G\left(g y, g g y_{n+1}, g g y_{n+1}\right)+G\left(g g y_{n+1}, F(y, x), F(y, x)\right) \\
= & G\left(g x, g g x_{n+1}, g g x_{n+1}\right)+G\left(g F\left(x_{n}, y_{n}\right), F(x, y), F(x, y)\right) \\
& +G\left(g y, g g y_{n+1}, g g y_{n+1}\right)+G\left(g F\left(y_{n}, x_{n}\right), F(y, x), F(y, x)\right) .
\end{aligned}
$$

Letting $n \rightarrow \infty$ in the above inequality, by using (2.15), (2.16) and the continuity of $g$, we conclude that

$$
0 \leq G(g x, F(x, y), F(x, y))+G(g y, F(y, x), F(y, x)) \leq 0 .
$$

By (G1), we have $g x=F(x, y)$ and $g y=F(y, x)$. Consequently, the element $(x, y) \in X \times X$ is a coupled coincidence point of the mappings $F$ and $g$.

Corollary 20 Let $(X, \preceq)$ be a partially ordered set and $(X, G)$ be a G-metric space such that $(X, G)$ is G-complete. Let $F: X \times X \rightarrow X$ and $g: X \rightarrow X$ be two mappings such that $F$ has the mixed $g$-monotone property on $X$ and

$$
\begin{aligned}
& G(F(x, y), F(u, v), F(u, v))+G(F(y, x), F(v, u), F(v, u)) \\
& \quad \leq k[G(g x, g u, g u)+G(g y, g v, g v)]
\end{aligned}
$$

for all $x, y, u, v \in X$ with $g x \succeq g u, g y \preceq g v$. Assume that $F(X \times X) \subset g(X)$, the self-mapping $g$ is G-continuous and $F$ and $g$ are G-compatible mappings. Suppose that either

(a) $F$ is continuous or

(b) $(X, G, \preceq)$ is g-ordered complete.

Suppose also that there exist $x_{0}, y_{0} \in X$ such that $g x_{0} \preceq F\left(x_{0}, y_{0}\right)$ and $g y_{0} \succeq F\left(y_{0}, x_{0}\right)$. If $k \in[0,1)$, then $F$ and $g$ have a coupled coincidence point.

Proof It is sufficient to take $z=u$ and $w=v$ in Theorem 19 .

Corollary 21 Let $(X, \preceq)$ be a partially ordered set and $(X, G)$ be a G-metric space such that $(X, G)$ is G-complete. Let $F: X \times X \rightarrow X$ and $g: X \rightarrow X$ be two mappings such that $F$ has the mixed $g$-monotone property on $X$ and

$$
\begin{aligned}
& G(F(x, y), F(u, v), F(w, z))+G(F(y, x), F(v, u), F(v, u)) \\
& \quad \leq k[G(g x, g u, g w)+G(g y, g v, g z)]
\end{aligned}
$$

for all $x, y, u, v \in X$ with $g x \succeq g u \succeq g w, g y \preceq g \nu \preceq g z$. Assume that $F(X \times X) \subset g(X)$ and that the self-mapping $g$ is G-continuous and commutes with F. Suppose that either

(a) $F$ is continuous or

(b) $(X, G, \preceq)$ is $g$-ordered complete.

Suppose further that there exist $x_{0}, y_{0} \in X$ such that $g x_{0} \preceq F\left(x_{0}, y_{0}\right)$ and $g y_{0} \succeq F\left(y_{0}, x_{0}\right)$. If $k \in[0,1)$, then $F$ and $g$ have a coupled coincidence point.

Proof Since $g$ commutes with $F$, then $F$ and $g$ are $G$-compatible mappings. Thus, the result follows from Theorem 19. 
Corollary 22 Let $(X, \preceq)$ be a partially ordered set and $(X, G)$ be a G-metric space such that $(X, G)$ is G-complete. Let $F: X \times X \rightarrow X$ and $g: X \rightarrow X$ be two mappings such that $F$ has the mixed $g$-monotone property on $X$ and

$$
\begin{aligned}
& G(F(x, y), F(u, v), F(u, v))+G(F(y, x), F(v, u), F(v, u)) \\
& \quad \leq k[G(g x, g u, g u)+G(g y, g v, g v)]
\end{aligned}
$$

for all $x, y, u, v \in X$ with $g x \succeq g u, g y \preceq g \nu$. Assume that $F(X \times X) \subset g(X)$ and that $g$ is G-continuous and commutes with $F$. Suppose that either

(a) $F$ is continuous or

(b) $(X, G, \preceq)$ is g-ordered complete.

Assume also that there exist $x_{0}, y_{0} \in X$ such that $g x_{0} \preceq F\left(x_{0}, y_{0}\right)$ and $g y_{0} \succeq F\left(y_{0}, x_{0}\right)$. If $k \in[0,1)$, then $F$ and $g$ have a coupled coincidence point.

Proof Since $g$ commutes with $F$, then $F$ and $g$ are $G$-compatible mappings. Thus, the result follows from Corollary 20.

Letting $g=I$ in Theorem 19 and in Corollary 20, we get the following results.

Corollary 23 Let $(X, \preceq)$ be a partially ordered set and $(X, G)$ be a G-metric space such that $(X, G)$ is $G$-complete. Let $F: X \times X \rightarrow X$ be a mapping having the mixed monotone property on $X$ and

$$
\begin{aligned}
& G(F(x, y), F(u, v), F(w, z))+G(F(y, x), F(v, u), F(v, u)) \\
& \quad \leq k[G(x, u, w)+G(y, v, z)]
\end{aligned}
$$

for all $x, y, u, v, z, w \in X$ with $x \succeq u \succeq w, y \preceq v \preceq z$. Suppose that either

(a) $F$ is continuous or

(b) $(X, G, \preceq)$ is ordered complete.

Suppose also that there exist $x_{0}, y_{0} \in X$ such that $x_{0} \preceq F\left(x_{0}, y_{0}\right)$ and $y_{0} \succeq F\left(y_{0}, x_{0}\right)$. If $k \in[0,1)$, then $F$ has a coupled fixed point.

Corollary 24 Let $(X, \preceq)$ be a partially ordered set and $(X, G)$ be a G-metric space such that $(X, G)$ is $G$-complete. Let $F: X \times X \rightarrow X$ be a mapping having the mixed monotone property on $X$ and

$$
\begin{aligned}
& G(F(x, y), F(u, v), F(u, v))+G(F(y, x), F(v, u), F(v, u)) \\
& \quad \leq k[G(x, u, u)+G(y, v, v)]
\end{aligned}
$$

for all $x, y, u, v \in X$ with $x \succeq u, y \preceq v$. Suppose that either

(a) $F$ is continuous or

(b) $(X, G, \preceq)$ is ordered complete.

Suppose further that there exist $x_{0}, y_{0} \in X$ such that $x_{0} \preceq F\left(x_{0}, y_{0}\right)$ and $y_{0} \succeq F\left(y_{0}, x_{0}\right)$. If $k \in[0,1)$, then $F$ has a coupled fixed point. 
Example 25 Let us recall Example 18. We have

$$
\begin{aligned}
& G(F(x, y), F(u, v), F(z, w))+G(F(y, x), F(v, u), F(w, z)) \\
& \quad=G\left(\frac{1}{8} x+\frac{5}{8} y, \frac{1}{8} u+\frac{5}{8} v, \frac{1}{8} z+\frac{5}{8} w\right)+G\left(\frac{1}{8} y+\frac{5}{8} x, \frac{1}{8} v+\frac{5}{8} u, \frac{1}{8} w+\frac{5}{8} z\right) \\
& \quad \leq \frac{6}{8}[(|u-x|+|z-x|+|z-u|)+(|v-y|+|w-y|+|w-v|)]
\end{aligned}
$$

and

$$
\begin{aligned}
G(g x, g u, g z)+G(g y, g v, g w)= & G\left(\frac{7 x}{8}, \frac{7 u}{8}, \frac{7 z}{8}\right)+G\left(\frac{7 y}{8}, \frac{7 v}{8}, \frac{w}{8}\right) \\
= & \frac{7}{8}[(|u-x|+|z-x|+|z-u|) \\
& +(|v-y|+|w-y|+|w-v|)] .
\end{aligned}
$$

It is clear that there any $k \in\left[\frac{6}{7}, 1\right)$ provides the statement $(2.3)$ of Theorem 19.

Notice that $(0,0)$ is the unique coupled coincidence point of $F$ and $g$ which is also common coupled fixed point, that is, $F(0,0)=g 0=0$.

Example 26 Let $X=\mathbb{R}$. Define $G: X \times X \times X \rightarrow[0, \infty)$ by

$$
G(x, y, z)=|x-y|+|x-z|+|y-z|
$$

for all $x, y, z \in X$. Let $\preceq$ be usual order. Then $(X, G)$ is a $G$-metric space.

Define a map $F: X \times X \rightarrow X$ by

$$
F(x, y)=\frac{1}{8} x^{3}+\frac{5}{8} y^{3}
$$

and $g: X \rightarrow X$ by $g(x)=x^{3}$ for all $x, y \in X$. Then $F(X \times X)=X=g(X)$. We observe that

$$
\begin{aligned}
G( & F(x, y), F(u, v), F(z, w))+G(F(y, x), F(v, u), F(v, u)) \\
= & G\left(\frac{1}{8} x^{3}+\frac{5}{8} y^{3}, \frac{1}{8} u^{3}+\frac{5}{8} v^{3}, \frac{1}{8} z^{3}+\frac{5}{8} w^{3}\right)+G\left(\frac{1}{8} y^{3}+\frac{5}{8} x^{3}, \frac{1}{8} v^{3}+\frac{5}{8} u^{3}, \frac{1}{8} w^{3}+\frac{5}{8} z^{3}\right) \\
= & \frac{5}{8}\left|v^{3}-y^{3}\right|+\frac{5}{8}\left|w^{3}-y^{3}\right|+\frac{5}{8}\left|w^{3}-v^{3}\right|+\frac{1}{8}\left|u^{3}-x^{3}\right|+\frac{1}{8}\left|z^{3}-x^{3}\right|+\frac{1}{8}\left|z^{3}-u^{3}\right| \\
& \quad+\frac{1}{8}\left|v^{3}-y^{3}\right|+\frac{1}{8}\left|w^{3}-y^{3}\right|+\frac{1}{8}\left|w^{3}-v^{3}\right|+\frac{5}{8}\left|u^{3}-x^{3}\right|+\frac{5}{8}\left|z^{3}-x^{3}\right|+\frac{5}{8}\left|z^{3}-u^{3}\right| \\
= & \frac{6}{8}\left[\left|v^{3}-y^{3}\right|+\left|w^{3}-y^{3}\right|+\left|w^{3}-v^{3}\right|+\left|u^{3}-x^{3}\right|+\left|z^{3}-x^{3}\right|+\left|z^{3}-u^{3}\right|\right]
\end{aligned}
$$

and

$$
\begin{aligned}
G(g x, g u, g z)+G(g y, g v, g w)= & G\left(x^{3}, u^{3}, z^{3}\right)+G\left(y^{3}, v^{3}, w^{3}\right) \\
= & \left(\left|x^{3}-u^{3}\right|+\left|x^{3}-z^{3}\right|+\left|u^{3}-z^{3}\right|\right) \\
& +\left(\left|y^{3}-v^{3}\right|+\left|y^{3}-w^{3}\right|+\left|v^{3}-w^{3}\right|\right),
\end{aligned}
$$

then the statement (2.3) of Theorem 19 is satisfied for any $k \in\left(\frac{3}{4}, 1\right)$ and $(0,0)$. 
Notice that if we replace the condition (2.3) of Theorem 19 with the condition (1.4) of Theorem 15 [21], that is,

$$
G(F(x, y), F(u, v), F(w, z)) \leq k[G(g x, g u, g w)+G(g y, g v, g z)]
$$

where $k \in\left[0, \frac{1}{2}\right)$, then the coupled coincidence point exists even though the contractive condition is not satisfied.

More precisely, consider $x=u=z$. Then we have

$$
\begin{aligned}
G(F(x, y), F(u, v), F(z, w)) & =G\left(\frac{1}{8} x^{3}+\frac{5}{8} y^{3}, \frac{1}{8} u^{3}+\frac{5}{8} v^{3}, \frac{1}{8} z^{3}+\frac{5}{8} w^{3}\right) \\
& =\frac{5}{8}\left|v^{3}-y^{3}\right|+\frac{5}{8}\left|w^{3}-y^{3}\right|+\frac{5}{8}\left|w^{3}-v^{3}\right|
\end{aligned}
$$

and

$$
\begin{aligned}
G(g x, g u, g z)+G(g y, g v, g w) & =G\left(x^{3}, u^{3}, z^{3}\right)+G\left(y^{3}, v^{3}, w^{3}\right) \\
& =\left|y^{3}-v^{3}\right|+\left|y^{3}-w^{3}\right|+\left|v^{3}-w^{3}\right| .
\end{aligned}
$$

It is clear that the condition (2.27) holds for $k>\frac{5}{8}$.

\section{Competing interests}

The authors declare that they have no competing interests.

\section{Authors' contributions}

All authors read and approved the final manuscript.

\section{Author details}

'Department of Mathematics, Atilim University, Incek, Ankara 06836, Turkey. ${ }^{2}$ Department of Mathematics, Faculty of Science, King Mongkut's University of Technology Thonburi (KMUTT), Bangkok, 10140, Thailand. ${ }^{3}$ Department of Mathematical and Statistical Sciences, University of Alberta, Edmonton, Alberta, Canada.

\section{Acknowledgements}

The second author gratefully acknowledges the support provided by the Department of Mathematics and Faculty of Science, King Mongkut's University of Technology Thonburi (KMUTT) during his stay at the Department of Mathematical and Statistical Sciences, University of Alberta as a visitor for the short term research.

Received: 7 July 2012 Accepted: 26 September 2012 Published: 11 October 2012

\section{References}

1. Fréchet, F: Sur quelques points du calcul fonctionnel. Rend. Circ. Mat. Palermo 22, 1-74 (1906)

2. Fenwick, DH, Batycky, RP: Using metric space methods to analyse reservoir uncertainty. In: Proceedings of the 2011 Gussow Conference. Banff, Alberta, Canada (2011)

3. Mustafa, Z, Sims, B: A new approach to generalized metric spaces. J. Nonlinear Convex Anal. 7(2), 289-297 (2006)

4. Mustafa, Z, Obiedat, H, Awawdeh, F: Some fixed point theorem for mapping on complete G-metric spaces. Fixed Point Theory Appl. 2008, Article ID 189870 (2008). doi:10.1155/2008/189870

5. Mustafa, Z, Khandaqji, M, Shatanawi, W: Fixed point results on complete G-metric spaces. Studia Sci. Math. Hung. 48, 304-319 (2011)

6. Mustafa, Z, Sims, B: Fixed point theorems for contractive mappings in complete $G$-metric spaces. Fixed Point Theory Appl. 2009, Article ID 917175 (2009). doi:10.1155/2009/917175

7. Mustafa, Z, Shatanawi, W, Bataineh, M: Existence of fixed point results in G-metric spaces. Int. J. Math. Math. Sci. 2009, Article ID 283028 (2009). doi:10.1155/2009/283028

8. Banach, S: Sur les opérations dans les ensembles abstraits et leur application aux équations intégrales. Fundam. Math. 3, 133-181 (1922)

9. Ran, ACM, Reurings, MCB: A fixed point theorem in partially ordered sets and some application to matrix equations. Proc. Am. Math. Soc. 132, 1435-1443 (2004)

10. Aydi, H, Damjanović, B, Samet, B, Shatanawi, W: Coupled fixed point theorems for nonlinear contractions in partially ordered G-metric spaces. Math. Comput. Model. 54, 2443-2450 (2011) 
11. Berinde, $\mathrm{V}$ : Generalized coupled fixed point theorems for mixed monotone mappings in partially ordered metric spaces. Nonlinear Anal. 74, 7347-7355 (2011)

12. Berinde, V: Coupled coincidence point theorems for mixed monotone nonlinear operators. Comput. Math. Appl. 64, 1770-1777 (2012)

13. Choudhury, BS, Kundu, A: A coupled coincidence point result in partially ordered metric spaces for compatible mappings. Nonlinear Anal. 73, 2524-2531 (2010)

14. Guo, D, Lakshmikantham, V: Coupled fixed points of nonlinear operators with applications. Nonlinear Anal., Theory Methods Appl. 11, 623-632 (1987)

15. Gnana-Bhaskar, T, Lakshmikantham, V: Fixed point theorems in partially ordered metric spaces and applications Nonlinear Anal. 65, 1379-1393 (2006)

16. Ćirić, LJ, Lakshmikantham, V: Coupled fixed point theorems for nonlinear contractions in partially ordered metric spaces. Nonlinear Anal. 70, 4341-4349 (2009)

17. Nieto, JJ, Lopez, RR: Contractive mapping theorems in partially ordered sets and applications to ordinary differential equations. Order 22, 223-239 (2005)

18. Luong, NV, Thuan, NX: Coupled fixed point theorems in partially ordered G-metric spaces. Math. Comput. Model. 55, 1601-1609 (2012)

19. Shatanawi, W: Fixed point theory for contractive mappings satisfying $\Phi$-maps in G-metric spaces. Fixed Point Theory Appl. 2010, Article ID 181650 (2010). doi:10.1155/2010/181650

20. Shatanawi, W: Some fixed point theorems in ordered G-metric spaces and applications. Abstr. Appl. Anal. 2011, Article ID 126205 (2011). doi:10.1155/2011/126205

21. Shatanawi, W: Coupled fixed point theorems in generalized metric spaces. Hacet. J. Math. Stat. 40, 441-447 (2011)

22. Shatanawi, W, Abbas, M, Nazir, T: Common coupled coincidence and coupled fixed point results in two generalized metric spaces. Fixed Point Theory Appl. 2011, Article ID 80 (2011). doi:10.1186/1687-1812-2011-80

23. Tahat, N, Aydi, H, Karapınar, E, Shatanawi, W: Common fixed points for single-valued and multi-valued maps satisfying a generalized contraction in G-metric spaces. Fixed Point Theory Appl. 2012, Article ID 48 (2012)

24. Abbas, M, Cho, YJ, Nazir, T: Common fixed points of Ciric-type contractive mappings in two ordered generalized metric spaces. Fixed Point Theory Appl. 2012, Article ID 139 (2012)

25. Cho, YJ, Rhoades, BE, Saadati, R, Samet, B, Shatanawi, W: Nonlinear coupled fixed point theorems in ordered generalized metric spaces with integral type. Fixed Point Theory Appl. 2012, Article ID 8 (2012)

26. Gordji, ME, Akbartabar, E, Cho, YJ, Ramezani, M: Coupled common fixed point theorems for mixed weakly monotone mappings in partially ordered metric spaces. Fixed Point Theory Appl. 2012, Article ID 95 (2012)

27. Huang, NJ, Fang, YP, Cho, YJ: Fixed point and coupled fixed point theorems for multi-valued increasing operators in ordered metric spaces. In: Cho, YJ, Kim, JK, Kang, SM (eds.) Fixed Point Theory and Applications, vol. 3, pp. 91-98. Nova Science Publishers, New York (2002)

28. Karapınar, E, Luong, NV, Thuan, NX, Hai, TT: Coupled coincidence points for mixed monotone operators in partially ordered metric spaces. Arab. J. Math. 1(3), 329-339 (2012)

29. Karapınar, E: Coupled fixed point theorems for nonlinear contractions in cone metric spaces. Comput. Math. Appl. 59 3656-3668 (2010)

30. Karapınar, E: Coupled fixed points on cone metric spaces. Gazi Univ. J. Sci. 24, 51-58 (2011)

31. Ding, HS, Li, L: Coupled fixed point theorems in partially ordered cone metric spaces. Filomat 25, 137-149 (2011)

32. Abbas, M, Sintunavarat, W, Kumam, P: Coupled fixed point of generalized contractive mappings on partially ordered G-metric spaces. Fixed Point Theory Appl. 2012, Article ID 31 (2012)

33. Aydi, H, Postolache, M, Shatanawi, W: Coupled fixed point results for $(\psi, \phi)$-weakly contractive mappings in ordered G-metric spaces. Comput. Math. Appl. 63, 298-309 (2012

34. Aydi, H, Karapınar, E, Shatnawi, W: Tripled fixed point results in generalized metric spaces. J. Appl. Math. 2012, Article ID 314279 (2012)

35. Nashine, HK: Coupled common fixed point results in ordered G-metric spaces. J. Nonlinear Sci. Appl. 1, 1-13 (2012)

doi:10.1186/1687-1812-2012-174

Cite this article as: Karapınar et al.: Coupled fixed point theorems on partially ordered G-metric spaces. Fixed Point

Theory and Applications 2012 2012:174.

\section{Submit your manuscript to a SpringerOpen ${ }^{\circ}$ journal and benefit from:}

- Convenient online submission

- Rigorous peer review

- Immediate publication on acceptance

- Open access: articles freely available online

- High visibility within the field

- Retaining the copyright to your article

Submit your next manuscript at $>$ springeropen.com 